\title{
Mechanical ventilation in obese ICU patients: from intubation to extubation
}

\author{
Audrey De Jong ${ }^{1,2}$, Gerald Chanques ${ }^{1,2}$ and Samir Jaber ${ }^{1,2^{*}}$
}

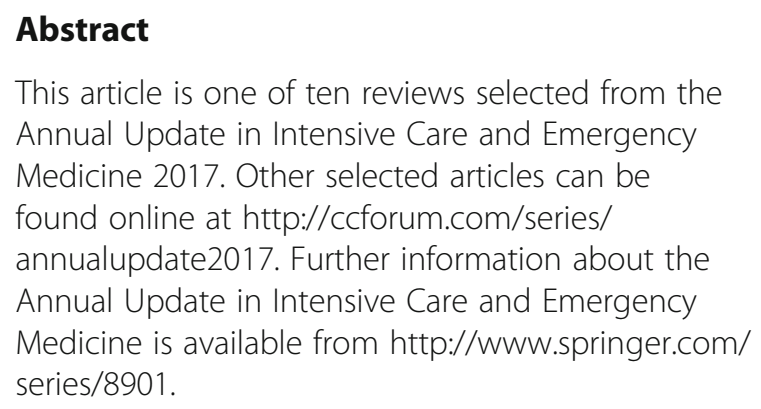

This article is one of ten reviews selected from the Annual Update in Intensive Care and Emergency Medicine 2017. Other selected articles can be found online at http://ccforum.com/series/ annualupdate2017. Further information about the Annual Update in Intensive Care and Emergency Medicine is available from http://www.springer.com/ series/8901.

\section{Background}

Obesity has become a worldwide health concern. The prevalence of obese adults in the United States of America has risen significantly over the last decade to $35 \%$ [1]. Bariatric surgery and complications associated with bariatric surgery are becoming increasingly frequent [2]. Obese patients represent a specific population in the intensive care unit [3]. Atelectasis formation is increased in obese patients, because of the negative effects of thoracic wall weight and abdominal fat mass on pulmonary compliance, leading to decreased functional residual capacity (FRC) and arterial oxygenation. These atelectases are further exacerbated by a supine position and further worsened after general anesthesia and mechanical ventilation. Atelectases contribute to hypoxemia during mechanical ventilation and after weaning from mechanical ventilation. More importantly, they persist after extubation in the obese patient in comparison with full resolution in non-obese patients [4], leading to pulmonary infections. Moreover, obese patients often present comorbidities, such as obstructive apnea syndrome or obesity hypoventilation syndrome. Obesity is a major risk factor for obstructive apnea syndrome (30 to $70 \%$ of subjects with obstructive apnea syndrome are obese). Many complications of respiratory care

\footnotetext{
* Correspondence: s-jaber@chu-montpellier.fr

${ }^{1}$ Anesthesia and Critical Care Department, Saint Eloi Teaching Hospital, University Montpellier 1, Intensive Care Unit, 80 avenue Augustin Fliche, 34295 Montpellier, Cedex 5, France

${ }^{2}$ CNRS UMR 9214, INSERM U1046, Montpellier, France
}

are directly related to the obstructive apnea syndrome: difficult airway management including difficult mask ventilation, difficult intubation and obstruction of the upper airway. The repetitive occurrence of rapid eye movement (REM) sleep, hypoventilation or obstructive sleep apnea with long-lasting apnea and hypopnea induces a secondary depression of respiratory drive with daytime hypercapnia, leading to obesity hypoventilation syndrome. Obesity hypoventilation syndrome is defined as a combination of obesity (body mass index $[\mathrm{BMI}] \geq 30 \mathrm{~kg} / \mathrm{m}^{2}$ ), daytime hypercapnia $\left(\mathrm{PaCO}_{2}>45 \mathrm{~mm} \mathrm{Hg}\right)$, and disordered breathing during sleep (after ruling out other disorders that might cause alveolar hypoventilation) [5].

However, while obesity contributes to many diseases and is associated with higher all-cause mortality in the general population [6], obesity and mortality in the intensive care unit (ICU) are inversely associated as shown by meta-analyses $[7,8]$. The "obesity paradox" phenomenon has recently become apparent in the ICU [9]. In particular, acute respiratory distress syndrome (ARDS) in obese patients, in whom diaphragmatic function is challenging, has a lower mortality risk when compared with non-obese patients $[10,11]$.

Obese patients can be admitted in a critical care setting for de novo acute respiratory failure, 'acute-on-chronic' respiratory failure with an underlying disease, such as an obesity hypoventilation syndrome, or in the perioperative period. The main challenges for ICU clinicians are to take into account the pulmonary pathophysiological specificities of the obese patient (detailed in Table 1) to optimize airway management and non-invasive or invasive mechanical ventilation.

\section{Physiology}

Oxygenation decreases with increase in weight, mostly because oxygen consumption and work of breathing are increased in obese patients [12]. At rest, oxygen consumption is 1.5 times higher in obese patients than in non-obese patients [12]. Obese patients have an excess production of carbon dioxide $\left(\mathrm{CO}_{2}\right)$, because of their 
Table 1 Pathophysiological specificities of the obese patient

\begin{tabular}{ll}
\hline 1. Lung volume & - Atelectasis in the dependent pulmonary area \\
& $-\searrow$ functional residual capacity (FRC) \\
& $-\nearrow$ intra-abdominal pressure \\
& - Diaphragm passively pushed cranially \\
& $-\searrow$ thoracic and pulmonary compliance \\
& $-\nearrow$ resistances (but normal after normalization to the functional lung volume) \\
& $-\nearrow$ work of breathing \\
& $-\nearrow$ risk factors for difficult mask ventilation (age $>55$ years old, snoring, beard, lack of teeth, \\
& obstructive apnea syndrome, associated congenital diseases) and difficult intubation (MACOCHA \\
2. Airway & score: Mallampati III or IV, obstructive apnea syndrome, limited mouth opening, reduced cervical \\
& mobility, coma, hypoxemia, operator not trained, associated congenital diseases) \\
& $-\searrow$ ventilatory response to hypercapnia and hypoxia in case of obesity hypoventilation syndrome \\
& $-\nearrow$ breath rate \\
& - Post-capillary pulmonary hypertension if associated cardiac dysfunction, pre-capillary if use of \\
& toxins (anorectics) \\
& $-\nearrow$ oxygen consumption \\
3. Ventilatory control & $-\nearrow$ carbon dioxide production \\
& - Obstructive apnea syndrome \\
5. Blood gas exchange & - Obesity hypoventilation syndrome \\
6. Comorbidities &
\end{tabular}

increased oxygen consumption and increased work of breathing, especially when there is an associated obesity hypoventilation syndrome, including a decreased respiratory drive [13]. In several studies, the spontaneous breath rate was from 15 to 21 breaths per minute in morbidly obese patients $\left(\mathrm{BMI}>40 \mathrm{~kg} / \mathrm{m}^{2}\right)$, whereas it was close to 10 to 12 in non-obese patients [14]. Moreover, abdominal pressure is increased because of increased abdominal and visceral adipose tissue deposition. The capacity of the chest is reduced compared to non-obese individuals, because the diaphragm is passively pushed cranially. Obese patients have decreased pulmonary and thoracic compliance, a reduction in FRC, and an increased work of breathing, compared to non-obese patients [15]. Airway resistance is increased, but not after normalization to the lung volume. The main change remains the decreased FRC, leading to more frequent atelectasis in obese than in non-obese patients after ventilation. Finally, as mentioned earlier, obesity is a major risk factor for obstructive apnea syndrome.

\section{Noninvasive respiratory management Non-invasive ventilation}

Non-invasive ventilation (NIV) may be applied to avoid intubation in obese patients with acute respiratory failure, without delaying intubation if needed. In hypercapnic obese patients, higher positive end-expiratory pressure (PEEP) might be used for longer periods to reduce the hypercapnia level below $50 \mathrm{mmHg}$ [16]. NIV is as efficient in patients with obesity hypoventilation syndrome as in patients with chronic obstructive pulmonary disease (COPD), in case of acute hypercapnic respiratory failure [17].

\section{High-flow nasal cannula oxygen}

High flow nasal cannula oxygen (HFNC) could be particularly interesting in obese patients. HNFC permits continuously humidified and warmed oxygen to be delivered through nasal cannula, with an adjustable fraction of inspired oxygen $\left(\mathrm{FiO}_{2}\right)$. The flow administered can reach 60 1/min with $100 \% \mathrm{FiO}_{2}$ [18]. A moderate level of PEEP has been measured with this device [18] when the patient breaths with a closed mouth. In case of hypoxemia, HNFC could be performed between sessions of NIV.

\section{Positioning}

Optimization of body position can enhance respiratory function in patients requiring mechanical ventilation. In healthy spontaneously breathing obese subjects, a significant reduction in pulmonary compliance was shown in the supine position [19]. A sitting position should therefore be privilegied in case of respiratory failure.

\section{Airway management \\ Pre-oxygenation \\ Facial mask}

Following pre-oxygenation, there is a reduction in the non-hypoxic apnea time (length of apnea following anesthetic induction during which the patient has no oxygen desaturation) in obese patients [20]. Using classic bag-mask ventilation as a method of pre-oxygenation, desaturation during intubation thus occurs within $3 \mathrm{~min}$ on average, sometimes less than one minute in severe obesity. The end-expiratory volume is reduced by $69 \%$ after anesthetic induction in the supine position, compared with baseline values [21]. The main cause of this rapid desaturation is the decrease in the FRC.

\section{Non-invasive ventilation}

Using a PEEP of $10 \mathrm{cmH}_{2} \mathrm{O}$ during pre-oxygenation is associated with a reduced atelectasis surface, improved 
oxygenation and increased time of apnea without hypoxemia by one minute on average [22]. Pre-oxygenation of 5 min with NIV, associating pressure support (PS) and PEEP, permits an exhaled fraction of oxygen $\left(\mathrm{FeO}_{2}\right)>$ $90 \%$ to be reached more quickly [23]. In another study, the use of NIV limited the decrease in pulmonary volume and improved oxygenation compared to conventional preoxygenation with a face mask [24]. Continuous positive airway pressure (CPAP) or NIV are therefore the reference pre-oxygenation methods (Fig. 1).

\section{High-flow nasal cannula oxygen}

HFNC may also be considered for pre-oxygenation of obese patients, including apneic oxygenation, enabling oxygen to be delivered during the apnea period (Fig. 1). This is particularly important in case of rapid sequence induction (RSI), where the obese patient does not receive oxygen between removal of the NIV mask and adequate positioning of the tracheal tube into the trachea.

\section{Positioning}

A sitting position during pre-oxygenation may decrease positional flow limitation and air trapping, limiting atelectasis and increasing oxygen desaturation during the intubation procedure (Fig. 1).

\section{Intubation}

Obesity and obstructive apnea syndrome, and a fortiori the combination of both, are risk factors for difficult intubation and difficult mask ventilation [3, 25]. Age > 55 years old, BMI $>26 \mathrm{~kg} / \mathrm{m}^{2}$, snoring, beard and lack of teeth are independent risk factors for difficult mask ventilation. Most of these factors are directly related to obesity. In the same way, tracheal intubation is more difficult in obese patients with obstructive apnea syndrome, with an incidence close to 15 to $20 \%$ (versus 2 to $5 \%$ in the general population), and associated with the severity of the obstructive apnea syndrome [26]. A recent study reported an increase in the incidence of difficult intubation in obese patients [3]. Moreover, in this study, elevated Mallampati score, limited mouth opening, reduced cervical mobility, presence of an obstructive apnea syndrome, coma and severe hypoxemia (risk factors included in the MACOCHA score [27]) were associated with difficult intubation in obese patients. Each intubation in a morbidly obese patient should be considered as difficult, and adequate preparation following an algorithm for difficult intubation performed (Fig. 1). Videolaryngoscopes are of particular interest in obese patients [28] and their use should be particularly emphasized when additional risk factors for difficult intubation are present.

\section{Extubation}

Obese patients are particularly at risk of post-extubation stridor [29]. A cuff-leak test [30] should be systematically performed in these patients, and in case of suspicion of laryngeal edema, prevention of stridor could be performed using a protocol of intravenous steroid administration, at least four hours before extubation, in the absence of contraindications [31].

\section{Mechanical ventilation \\ Protective ventilation \\ Tidal volume}

In patients with pulmonary lesions, such as ARDS, the benefits of ventilation with low tidal volumes $(6 \mathrm{ml} / \mathrm{kg})$ has been widely demonstrated [32]. Since 2010, protective perioperative ventilation has been studied more closely. In the setting of abdominal surgery, the IMPROVE multicenter, randomized, double-blinded study [33], compared an "optimized" strategy of ventilation called "protective ventilation" (tidal volume $6-8 \mathrm{ml} / \mathrm{kg}$ of ideal body weight [IBW], PEEP $6-8 \mathrm{cmH}_{2} \mathrm{O}$, systematic alveolar recruitment maneuvers every $30 \mathrm{~min}$ ) with a "traditional" strategy called "non-protective ventilation" (tidal volume $10-12 \mathrm{ml} / \mathrm{kg}$ of IBW, without PEEP or recruitment maneuvers). The included patients had a moderate risk of postoperative pulmonary complications. Patients with a BMI $>40 \mathrm{~kg} / \mathrm{m}^{2}$ were excluded. The main endpoint was a composite criterion including the onset of pulmonary complications (pulmonary infections or need for ventilation) and/or extrapulmonary complications (sepsis, septic shock, death) diagnosed by an observer blinded to the perioperative ventilator settings. Protective ventilation enabled a decrease in the global rate of complications from $27.5 \%$ to $10.5 \%$ and in the length of hospitalization by two days. In the randomized European PROVHILO study [34] including patients at risk of postoperative pulmonary complications after abdominal surgery, two ventilation strategies were compared. All the patients received a tidal volume of $8 \mathrm{ml} / \mathrm{kg}$ of IBW and were randomized into two groups: one group with low PEEP $\left(\leq 2 \mathrm{cmH}_{2} \mathrm{O}\right)$ without recruitment maneuvers and a group with high PEEP $\left(12 \mathrm{cmH}_{2} \mathrm{O}\right)$ with recruitment maneuvers. There was no significant difference between the two groups for the main endpoint, which was a composite of postoperative pulmonary complications in the five first days following surgery. There were significantly more cases of hemodynamic failure in the group with high PEEP. These two large randomized studies are complementary: while the first showed the usefulness of protective ventilation to decrease pulmonary and extrapulmonary postoperative complications, the second warns against the hemodynamic dangers of excessively high levels of PEEP for all patients, in particular when high PEEP levels are not associated with low tidal volume. 


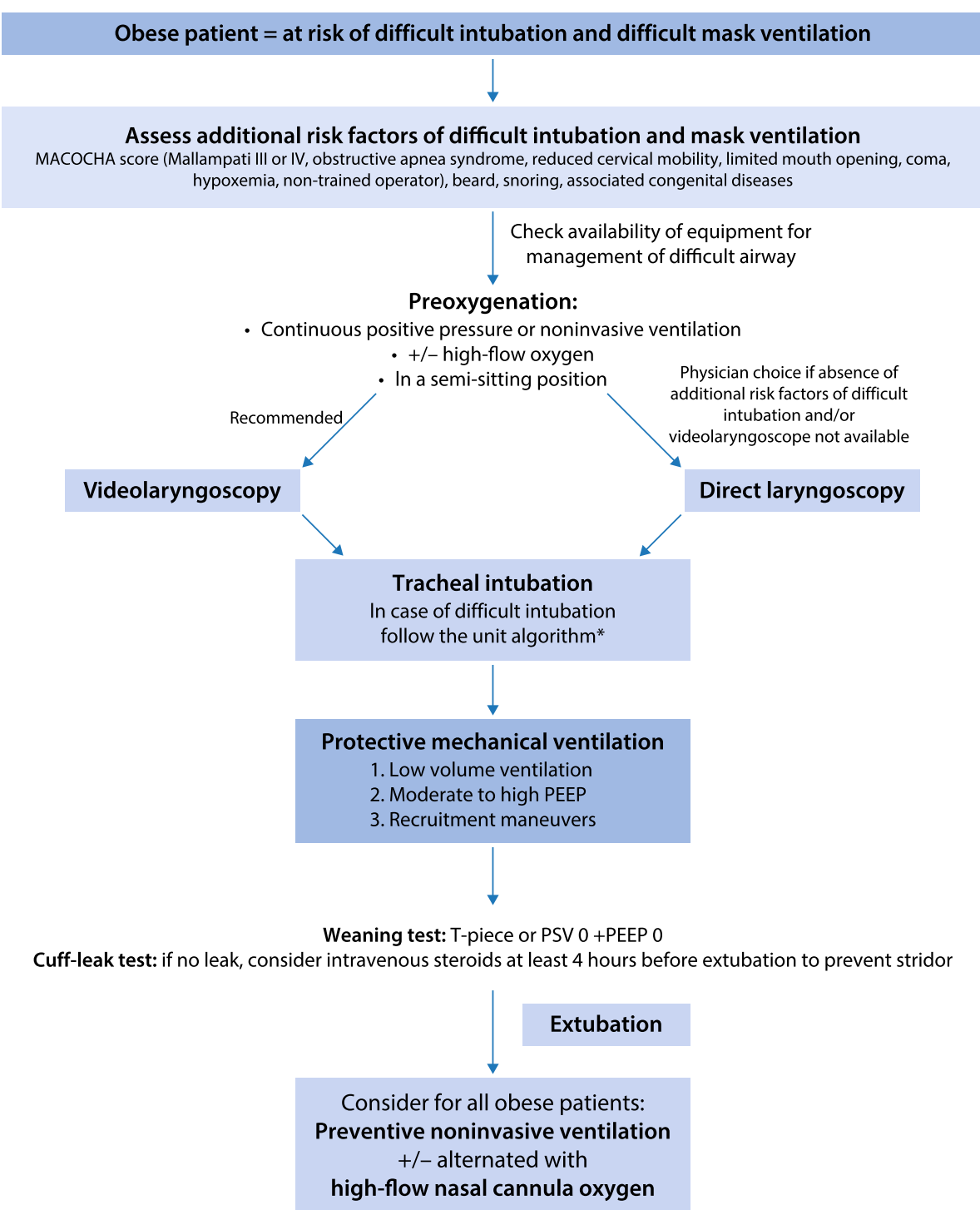

Fig. 1 Suggested airway and ventilation management algorithm in the obese patient in the intensive care unit. During the whole procedure, the patient should be ventilated in case of desaturation $<80 \%$. In case of non-adequate ventilation and unsuccessful intubation, emergency non-invasive airway ventilation (supraglottic airway) must be used. *In case of difficult intubation (multiple attempts), follow an intubation airway algorithm nonspecific to obese patients (for example see [50]). PEEP: positive end-expiratory pressure; PSV: pressure support ventilation

In obese patients, particularly at risk of atelectasis, the same rules can be applied. In spite of these recommendations, a recent study showed that obese patients were still ventilated in the perioperative period with tidal volumes that were too high [35]. In obese as in non-obese patients, the optimal tidal volume is between 6 to $8 \mathrm{ml} /$ $\mathrm{kg}$ of IBW associated with PEEP to avoid atelectasis by alveolar closing (derecruitment). The tidal volume setting must be guided by the patient's height and not by his/her measured weight. The easiest formula for calculation of IBW to remember is the following: IBM $(\mathrm{kg})=$ height $(\mathrm{cm})-100$ for a man and height $(\mathrm{cm})-110$ for a woman.

\section{Positive end-expiratory pressure}

Given their decreased FRC, obese patients are more sensitive than non-obese patients to atelectasis and lack of PEEP. In several studies specifically performed in obese patients, respiratory mechanics and alveolar recruitment have been shown to be significantly improved by application of PEEP (improvement in compliance and decreased inspiratory resistance), as has gas exchange [36]. Moreover, the PEEP levels used help prevent derecruitment (alveolar closing) due to FRC decrease, but do not open alveoli once they are collapsed. It is consequently better to apply, from the start of mechanical ventilation and during the whole period of ventilation, a PEEP of 10 
$\mathrm{cmH}_{2} \mathrm{O}$ associated with a tidal volume of 6 to $8 \mathrm{ml} / \mathrm{kg}$ of IBW $[24,37]$. However, it is necessary to remain on guard and always assess the hemodynamic effects of high PEEP: risk of decreased oxygenation because of an impact on cardiac flow and of hypotension because of compromised venous drainage. In case of auto-PEEP, application of a PEEP will depend on the presence or not of a limitation in expiratory flow because of airway collapse during expiration. If this phenomenon exists, an extrinsic PEEP of $2 / 3$ of the intrinsic PEEP should be applied.

The optimal level of PEEP in obese patients and the best means of titrating PEEP are still unknown. Some obese patients may benefit from higher levels of PEEP than others. Measuring transdiaphragmatic pressure seems crucial to determine the maximum pressure minimizing alveolar damage, taking into account that the plateau pressure is related to both transthoracic and transalveolar pressures.

\section{Recruitment maneuvers}

To open alveoli once they are closed, recruitment maneuvers should be used, transitorily increasing the transpulmonary pressure. The impact of these maneuvers in the obese patient has been shown to improve arterial oxygenation and available lung volume [24].

The best recruitment maneuver has not been determined in the obese patient. Recruitment maneuvers are mandatory to fully reopen the lung after anesthesia induction and a PEEP must be applied to prevent the progressive closing of the lung leading to atelectasis. The optimal level of PEEP during protective ventilation remains to be determined, but many physiological studies suggest that PEEP levels of at least $5 \mathrm{cmH}_{2} \mathrm{O}$ are necessary, in particular in obese patients. Levels of pressure needed to open the alveoli seem to be higher than in the non-obese patient, mostly because of the increased transthoracic pressure. Questions persist regarding the type of recruitment maneuver to recommend. The reference method is an expiratory pause with a PEEP level of $40 \mathrm{cmH}_{2} \mathrm{O}$ during $40 \mathrm{~s}$, but many alternatives exist, including progressive increase in PEEP until $20 \mathrm{cmH}_{2} \mathrm{O}$ with a constant tidal volume within $35 \mathrm{cmH}_{2} \mathrm{O}$ of plateau pressure, or a progressive increase in the tidal volume [38]. These recruitment maneuvers can be performed only if they are hemodynamically well tolerated. The ideal frequency for recruitment maneuvers has still not been determined.

\section{Driving pressure}

Driving pressure is the difference between inspiratory plateau pressure and end-expiratory pressure. The concept of driving pressure assumes that functional lung size is better quantified by compliance than by predicted body weight. This concept explains why ventilator-induced lung injury
(VILI), cyclic strain and survival may be better correlated with driving pressure than with tidal volume. Lower levels of driving pressure have been found to be associated with increased survival in ICU patients [39]. The ventilatory setting during mechanical ventilation, especially in obese patients, should be set to minimize driving pressure.

\section{Respiratory rate}

Concerning the setting or respiratory rate, obese patients have an excess production of $\mathrm{CO}_{2}$, because of their increased oxygen consumption and increased work of breathing, especially when there is an associated obesity hypoventilation syndrome, with a decreased respiratory drive [13]. In four studies, the spontaneous breath rate was from 15 to 21 breaths per minute in morbidly obese patients (BMI $>40 \mathrm{~kg} / \mathrm{m}^{2}$ ), whereas it was close to 10 to 12 in non-obese patients [14]. Ventilation should, therefore, be adapted, essentially increasing breath rate.

\section{Ventilatory mode}

Which ventilator mode is better in obese patients? The pressure modes deliver a constant pressure in the airway, decreasing the risk of barotrauma, with an insufflating pressure set at less than $30 \mathrm{cmH}_{2} \mathrm{O}$. In case of increase in airway resistance (bronchospasm, obstructed tube) or decrease in compliance of the respiratory system (obesity, atelectasis, selective intubation, surgical pneumoperitoneum, pneumothorax ...), the tidal volume decreases, leading to hypercapnia acidosis if alveolar ventilation is too low. It is consequently important to carefully check tidal volume, minute ventilation and capnography when using a pressure mode. The use of a volume mode carries the risk of an increase in the insufflation pressure to deliver the required tidal volume (risk of barotrauma), hence the importance of checking the alveolar pressure at the end of inspiration, i. e., the plateau pressure.

In obese patients, some teams recommend the pressure controlled mode because the decelerating flow should allow a better distribution of the flow in the alveoli. However, studies comparing the two ventilatory modes report contradictory data: discordances can be explained by the different inclusion criteria and the methodological limitations of the studies [40]. In practice, the advantages and inconveniences of each mode must be known and the ventilatory mode that the physician prefers used.

Pressure support ventilation (PSV) seems very interesting in obese patients. In obese piglets, it was shown that PSV improved oxygenation and decreased inflammation [41]. In the obese patient, postoperative pulmonary complications were decreased by the use of PSV compared to pressure controlled ventilation [42]. In anesthesia as in the ICU, in obese ventilated patients, the scientific evidence is still weak and future studies are necessary to compare PSV, new ventilatory modes, such as neurally-adjusted 
ventilatory assist (NAVA), adaptive support ventilation (ASV), and proportional assist ventilation (PAV), with conventional pressure or volume controlled modes.

\section{Positioning}

In the supine position, positional flow limitation and air trapping impedes respiratory management particularly in obese patients [43]. A sitting position during mechanical ventilation is therefore advised. Prone positioning in obese ARDS patients enables an improvement in the partial arterial pressure of oxygen $\left(\mathrm{PaO}_{2}\right) / \mathrm{FiO}_{2}$ ratio more than in the non-obese patient, and is not associated with more complications [10].

\section{Weaning from mechanical ventilation}

A recent physiological study specifically investigated the inspiratory effort during weaning of mechanical ventilation in a population of critically ill, morbidly obese patients [44]. The main result of this study was that for obese patients, T-piece and PSV $0+$ PEEP $0 \mathrm{cmH}_{2} \mathrm{O}$ weaning tests were the tests that best predicted postextubation inspiratory effort and work of breathing ([44]; Fig. 1). Following extubation, positive protective ventilation should be pursued, both in the ICU and in the recovery room. Postoperative CPAP or NIV might be extended to all obese patients, even those without obstructive apnea syndrome.

\section{Specific settings}

\section{Acute-on-chronic respiratory failure}

Prevention of relapses of acute-on-chronic respiratory failure are essential and should be ensured by the intensivist. Positive airway pressure therapies can be implemented in the ICU and continued at home, with the support of home therapists. Sleep-related breathing disorders, including obesity hypoventilation syndrome, should be followed by a specialist after ICU discharge, ideally in the setting of a multidisciplinary obesity team.

\section{Perioperative management}

In obese patients with obstructive apnea syndrome, nocturnal CPAP should be initiated before surgery, especially if the apnea hypopnea index (AHI) is more than 30 events per hour or if there is severe cardiovascular comorbidity. If CPAP or NIV were used prior to surgery, they should be pursued throughout the perioperative period, including the postoperative period.

The risk factors for postoperative respiratory failure include the severity of obstructive apnea syndrome, the intravenous administration of opioids, the use of sedatives, the site (close to the diaphragm) and the invasive nature of the surgical procedure, and the apnea onset during paradoxical sleep on the third or fourth postoperative day.
Some postoperative interventions that can decrease the risk of respiratory failure are a postoperative analgesia strategy sparing opioids, oxygenation by CPAP or $\mathrm{NIV}$, careful patient positioning and monitoring. CPAP or NIV must be resumed in the recovery room [45]. Compliance to CPAP or NIV will be better if the patients bring their own equipment to the hospital. In case of frequent or severe hypoxemias, start of CPAP or NIV should not be delayed. If possible, the supine position should be avoided in patients with an obstructive apnea syndrome at risk of postoperative pulmonary complications, and a sitting position adopted. The prophylactic application of NIV after extubation decreases the risk of acute respiratory failure by $16 \%$ and reduces length of stay [45]. Moreover, in obese hypercapnic patients, the use of NIV following extubation is associated with decreased mortality [46]. A randomized controlled trial performed in morbidly obese patients after bariatric surgery reported an improvement in ventilatory function when CPAP was immediately implemented after extubation compared to CPAP started $30 \mathrm{~min}$ following extubation [47]. Hence, NIV associating pressure support and PEEP or CPAP alone must be used liberally in the postoperative period, in order to reduce the aggravation of atelectasis, a long period of oxygen dependence and consequently the patients' length of stay in the post-surgical unit and in the hospital [45]. Among patients with hypoxemic respiratory failure following abdominal surgery, use of NIV compared with standard oxygen therapy reduced the risk of tracheal reintubation within 7 days [48]. These findings support the use of NIV in this setting.

Oxygen supplementation should be administered continuously to all patients with obstructive apnea syndrome at increased perioperative risk until they are able to maintain their baseline oxygen saturation on ambient air; oxygen saturations should be monitored after leaving the recovery room [49].

Respiratory physiotherapy and patient education of exercises, such as incentive spirometry or high volume respiration, also limit the reduction in lung volume induced by surgery.

\section{Conclusion}

Obese patients admitted to the ICU are at risk of atelectasis, which is associated with pulmonary complications. NIV can be safely and efficiently used to prevent and/or treat acute respiratory failure, without delaying intubation if needed. HNFC enable continuously humidified and warmed oxygen to be delivered through nasal cannula, with an adjustable $\mathrm{FiO}_{2}$, with a flow reaching $60 \mathrm{l} /$ min and providing a moderate level of PEEP. Because of the increased incidence of difficult mask ventilation and intubation in obese patients, a protocol of difficult airway-management should be systematically applied to 
prevent the complications related to the intubation-procedure (severe hypoxemia, arterial hypotension and cardiac arrest). Pre-oxygenation should be optimized using positive-pressure ventilation (CPAP or NIV) in a semisitting position, eventually added to apneic oxygenation using HFNC in the more severely obese patients. After tracheal intubation, to avoid both baro-volutrauma and atelecto-biotrauma, association of low tidal volume, moderate to high PEEP and recruitment maneuvers (lung protective ventilation) should be applied. The height of the lung being correlated to the height of the patient, tidal volume should be set according to IBW and not actual body weight, between 6 and $8 \mathrm{ml} / \mathrm{kg}$ IBW. In patients with ARDS, prone position is a safe procedure which permits respiratory mechanic improvements and oxygenation. Obstructive-apnea syndrome and obesity-hypoventilation syndrome should be investigated to introduce appropriate treatment, including implementation of positive airway pressure at home.

\section{Acknowledgements}

Not applicable.

\section{Funding}

Support was provided solely from institutional and/or departmental sources. Publication costs were funded by the "Centre Hospitalier Universitaire (CHU) Montpellier.

\section{Availability of data and materials}

Not applicable.

\section{Authors' contributions}

ADJ, GC and SJ contributed to drafting the submitted article, and to provide final approval of the version to be published.

\section{Competing interests}

The authors declare that they have no competing interests.

\section{Consent for publication}

Not applicable.

\section{Ethics approval and consent to participate}

No applicable.

Published online: 21 March 2017

\section{References}

1. NCD Risk Factor Collaboration (NCD-RisC). Trends in adult body-mass index in 200 countries from 1975 to 2014: a pooled analysis of 1698 population-based measurement studies with 19.2 million participants. Lancet. 2016;387:1377-96.

2. Montravers P, Ribeiro-Parenti L, Welsch C. What's new in postoperative intensive care after bariatric surgery? Intensive Care Med. 2015;41:1114-7.

3. De Jong A, Molinari N, Pouzeratte $Y$, et al. Difficult intubation in obese patients: incidence, risk factors, and complications in the operating theatre and in intensive care units. $\mathrm{Br} J$ Anaesth. 2015;114:297-306.

4. Eichenberger A, Proietti S, Wicky S, et al. Morbid obesity and postoperative pulmonary atelectasis: an underestimated problem. Anesth Analg. 2002;95: 1788-92.

5. Pepin JL, Timsit JF, Tamisier R, Borel JC, Levy P, Jaber S. Prevention and care of respiratory failure in obese patients. Lancet Respir Med. 2016;4:407-18.

6. Flegal KM, Kit BK, Orpana H, Graubard BI. Association of all-cause mortality with overweight and obesity using standard body mass index categories: a systematic review and meta-analysis. JAMA. 2013;309:71-82.

7. Hogue CW, Stearns JD, Colantuoni E, et al. The impact of obesity on outcomes after critical illness: a meta-analysis. Intensive Care Med. 2009;35:1152-70.
8. Akinnusi ME, Pineda LA, El Solh AA. Effect of obesity on intensive care morbidity and mortality: a meta-analysis. Crit Care Med. 2008;36:151-8.

9. De Jong A, Jung B, Chanques G, Jaber S, Molinari N. Obesity and mortality in critically ill patients: another case of the simpson paradox? Chest. 2012; 141:1637-8

10. De Jong A, Molinari N, Sebbane $M$, et al. Feasibility and effectiveness of prone position in morbidly obese patients with ARDS: A case-control clinical study. Chest. 2013;143:1554-61.

11. O'Brien Jr JM, Philips GS, Ali NA, Aberegg SK, Marsh CB, Lemeshow S. The association between body mass index, processes of care, and outcomes from mechanical ventilation: a prospective cohort study. Crit Care Med. 2012:40:1456-63.

12. Kress JP, Pohlman AS, Alverdy J, Hall JB. The impact of morbid obesity on oxygen cost of breathing (VO(2RESP)) at rest. Am J Respir Crit Care Med. 1999:160:883-6.

13. Pepin J, Borel JC, Janssens JP. Obesity hypoventilation syndrome: an underdiagnosed and undertreated condition. Am J Respir Crit Care Med. 2012;186:1205-7.

14. Chlif M, Keochkerian D, Choquet D, Vaidie A, Ahmaidi S. Effects of obesity on breathing pattern, ventilatory neural drive and mechanics. Respir Physiol Neurobiol. 2009;168:198-202

15. Pelosi P, Croci M, Ravagnan I, Vicardi P, Gattinoni L. Total respiratory system, lung, and chest wall mechanics in sedated-paralyzed postoperative morbidly obese patients. Chest. 1996;109:144-51.

16. Gursel G, Aydogdu M, Gulbas G, Ozkaya S, Tasyurek S, Yildirim F. The influence of severe obesity on non-invasive ventilation (NIV) strategies and responses in patients with acute hypercapnic respiratory failure attacks in the ICU. Minerva Anestesiol. 2011;77:17-25.

17. Carrillo A, Ferrer M, Gonzalez-Diaz G, et al. Noninvasive ventilation in acute hypercapnic respiratory failure caused by obesity hypoventilation syndrome and chronic obstructive pulmonary disease. Am J Respir Crit Care Med. 2012;186:1279-85.

18. Chanques G, Riboulet F, Molinari N, et al. Comparison of three high flow oxygen therapy delivery devices: a clinical physiological cross-over study. Minerva Anestesiol. 2013;79:1344-55.

19. Naimark A, Cherniack RM. Compliance of the respiratory system and its components in health and obesity. J Appl Physiol. 1960;15:377-82.

20. De Jong A, Futier $E_{1}$ Millot $A$, et al. How to preoxygenate in operative room: Healthy subjects and situations "at risk". Ann Fr Anesth Reanim. 2014;33:457-61.

21. Futier $\mathrm{E}$, Constantin JM, Petit $\mathrm{A}$, et al. Positive end-expiratory pressure improves end-expiratory lung volume but not oxygenation after induction of anaesthesia. Eur J Anaesthesiol. 2010;27:508-13.

22. Gander S, Frascarolo P, Suter M, Spahn DR, Magnusson L. Positive end-expiratory pressure during induction of general anesthesia increases duration of nonhypoxic apnea in morbidly obese patients. Anesth Analg. 2005;100:580-4.

23. Delay JM, Sebbane M, Jung B, et al. The effectiveness of noninvasive positive pressure ventilation to enhance preoxygenation in morbidly obese patients: a randomized controlled study. Anesth Analg. 2008;107:1707-13.

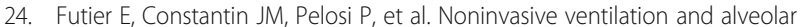
recruitment maneuver improve respiratory function during and after intubation of morbidly obese patients: a randomized controlled study. Anesthesiology. 2011;114:1354-63.

25. Langeron $\mathrm{O}$, Masso $\mathrm{E}_{1}$ Huraux $\mathrm{C}$, et al. Prediction of difficult mask ventilation. Anesthesiology. 2000;92:1229-36.

26. Siyam MA, Benhamou D. Difficult endotracheal intubation in patients with sleep apnea syndrome. Anesth Analg. 2002;95:1098-102.

27. De Jong A, Molinari $N$, Terzi $N$, et al. Early identification of patients at risk for difficult intubation in the intensive care unit: development and validation of the MACOCHA score in a multicenter cohort study. Am J Respir Crit Care Med. 2013;187:832-9.

28. Andersen LH, Rovsing L, Olsen KS. GlideScope videolaryngoscope vs. Macintosh direct laryngoscope for intubation of morbidly obese patients: a randomized trial. Acta Anaesthesiol Scand. 2011;55:1090-7.

29. Frat JP, Gissot V, Ragot S, et al. Impact of obesity in mechanically ventilated patients: a prospective study. Intensive Care Med. 2008;34:1991-8.

30. Jaber S, Chanques G, Matecki S, et al. Post-extubation stridor in intensive care unit patients. Risk factors evaluation and importance of the cuff-leak test. Intensive Care Med. 2003:29:69-74.

31. Jaber $S$, Jung B, Chanques $G$, Bonnet F, Marret E. Effects of steroids on reintubation and post-extubation stridor in adults: meta-analysis of randomised controlled trials. Crit Care. 2009;13:R49. 
32. Petrucci N, De Feo C. Lung protective ventilation strategy for the acute respiratory distress syndrome. Cochrane Database Syst Rev. 2013;CD003844

33. Futier $\mathrm{E}$, Constantin JM, Paugam-Burtz $\mathrm{C}$, et al. A trial of intraoperative lowtidal-volume ventilation in abdominal surgery. N Engl J Med. 2013;369:428-37.

34. Hemmes SN, Gama de Abreu M, Pelosi P, Schultz MJ. High versus low positive end-expiratory pressure during general anaesthesia for open abdominal surgery (PROVHILO trial): a multicentre randomised controlled trial. Lancet. 2014;384:495-503.

35. Jaber S, Coisel Y, Chanques G, et al. A multicentre observational study of intra-operative ventilatory management during general anaesthesia: tidal volumes and relation to body weight. Anaesthesia. 2012;67:999-1008.

36. Pelosi P, Croci M, Ravagnan I, et al. Respiratory system mechanics in sedated, paralyzed, morbidly obese patients. J Appl Physiol. 1997;82:811-8.

37. Talab HF, Zabani IA, Abdelrahman HS, et al. Intraoperative ventilatory strategies for prevention of pulmonary atelectasis in obese patients undergoing laparoscopic bariatric surgery. Anesth Analg. 2009;109:1511-6.

38. Constantin JM, Jaber S, Futier $\mathrm{E}$, et al. Respiratory effects of different recruitment maneuvers in acute respiratory distress syndrome. Crit Care. 2008;12:R50.

39. Amato MB, Meade MO, Slutsky AS, et al. Driving pressure and survival in the acute respiratory distress syndrome. N Engl J Med. 2015;372:747-55.

40. Aldenkortt M, Lysakowski C, Elia N, Brochard L, Tramer MR. Ventilation strategies in obese patients undergoing surgery: a quantitative systematic review and meta-analysis. Br J Anaesth. 2012;109:493-502.

41. Spieth PM, Carvalho AR, Güldner A, et al. Pressure support improves oxygenation and lung protection compared to pressure-controlled ventilation and is further improved by random variation of pressure support. Crit Care Med. 2011;39:746-55.

42. Zoremba M, Kalmus G, Dette F, Kuhn C, Wulf H. Effect of intra-operative pressure support vs pressure controlled ventilation on oxygenation and lung function in moderately obese adults. Anaesthesia. 2010;65:124-9.

43. Lemyze M, Mallat J, Duhamel A, et al. Effects of sitting position and applied positive end-expiratory pressure on respiratory mechanics of critically ill obese patients receiving mechanical ventilation. Crit Care Med. 2013;41:2592-9.

44. Mahul M, Jung B, Galia F, et al. Spontaneous breathing trial and postextubation work of breathing in morbidly obese critically ill patients. Crit Care. 2016;20:346

45. Jaber S, Chanques G, Jung B. Postoperative noninvasive ventilation. Anesthesiology. 2010;112:453-61.

46. El-Solh AA, Aquilina A, Pineda L, Dhanvantri V, Grant B, Bouquin P. Noninvasive ventilation for prevention of post-extubation respiratory failure in obese patients. Eur Respir J. 2006;28:588-95.

47. Neligan PJ, Malhotra G, Fraser M, et al. Continuous positive airway pressure via the Boussignac system immediately after extubation improves lung function in morbidly obese patients with obstructive sleep apnea undergoing laparoscopic bariatric surgery. Anesthesiology. 2009;110:878-84.

48. Jaber S, Lescot T, Futier E, et al. Effect of noninvasive ventilation on tracheal reintubation among patients with hypoxemic respiratory failure following abdominal surgery: a randomized clinical trial. JAMA. 2016;315:1345-53.

49. Bolden N, Smith CE, Auckley D, Makarski J, Avula R. Perioperative complications during use of an obstructive sleep apnea protocol following surgery and anesthesia. Anesth Analg. 2007;105:1869-70.

50. De Jong A, Jung B, Jaber S. Intubation in the ICU: we could improve our practice. Crit Care. 2014;18:209. 